\title{
TINJAUAN KRIMINOLOGI TERHADAP FAKTOR PENYEBAB PELANGGARAN RAMBU LALULINTAS OLEH PENGENDARA SEPEDA MOTOR DI KOTA SEMARANG
}

\author{
Oleh \\ Yesi Putri Utami
}

\begin{abstract}
The purpose of this study are (1) to analyze the factors that cause violations of traffic signs by motorcycle riders in the city of Semarang. (2) To analyze criminological studies of violations of traffic signs by motorcyclists in Semarang City.

The approach method is done juridically sociologically, specification descriptively using primary data and secondary data, through interviews and literature, then analyzed qualitatively.

The results of the discussion show that (1) the factors that cause violations of traffic signs by motorcyclists in Semarang City are human factors, among others, the driver's indiscipline, the intent of the driver and the pretense of the driver. (2) Criminological study of violations of traffic signs by motorcycle riders in the city of Semarang, namely the presence of awareness, discipline, public interest in having a vehicle, incompetence factor
\end{abstract}

Keywords: Criminology, Violation of Traffic Signs, Motorcycle Riders

\begin{abstract}
ABSTRAK
Tujuan penelitian ini adalah (1) Untuk menganalisis faktor-faktor yang menyebabkan pelanggaran rambu lalu lintas oleh pengendara sepeda motor di Kota Semarang.(2) Untuk menganalisiskajian kriminologi terhadap pelanggaran rambu lalu lintas oleh pengendara sepeda motor di Kota Semarang

Metode pendekatan dilakukan secara yuridis sosiologis, spesifikasi secara deskriptif dengan menggunakan data primer dan data sekunder, melalui wawancara dan kepustakaan, kemudian dianalisa secara kualitatif.

Hasil pembahasan menunjukkan bahwa (1)Faktor-faktor yang menyebabkan pelanggaran rambu lalu lintas oleh pengendara sepeda motor di Kota Semarang adalah faktor manusia antara lain ketidakdisplinan pengendara, kesengajaan pengendara dan kepura-puraan pengendara. (2) Kajian kriminologi terhadap pelanggaran rambu lalu lintas oleh pengendara sepeda motor di kota Semarang yaitu adanya faktor kesadaram, kedisiplinan, minat masyarakat mempunyai kendaraan, faktor ketidakjeraan
\end{abstract}

Kata Kunci : Kriminologi, Pelanggaran Rambu Lalu Lintas, Pengendara Sepeda Motor 


\section{Latar Belakang}

Dalam era globalisasi seperti saat ini masyarakat dituntut untuk memiliki mobilitas tinggi, khususnya masyarakat yang bertempat tinggal di perkotaan. Setiap harinya masyarakat perkotaan melakukan mobilitas untuk memenuhi kebutuhannya seperti ke kantor, ke sekolah, ke kampus bahkan berlibur, oleh karena itu dalam menunjang tingkat mobilitasnya dibutuhkan suatu alat atau moda transportasi. Salah satunya di bidang transportasi darat yang pesat perkembangannya adalah kendaraan bermotor atau sepeda motor.Perkembangan yang pesat itu seharusnya diimbangi dengan sarana lalu lintas jalan raya.Hal ini dengan tujuan untuk mengatasi jumlah kendaraan yang kian hari kian membludak.Semakin membludaknya kendaraan di jalan raya sering menimbulkan pelanggaran lalu lintas. Pelanggaran lalu lintas merupakan suatu keadaan dimana terjadi ketidak sesuaian antara aturan dan pelaksanaan.Aturan dalam hal ini yang dimaksud adalah Undang-Undang yang telah ditetapkan oleh negara yang berlaku secara sah, sedangkan masyarakat menjadi pelaksananya. Dalam mengikuti aturan yang tertera dalam pasal-pasal jika tidak sesuai dengan pasal-pasal tersebut, maka disebut pelanggaran lalu lintas. Dalam kriminologi kajian tentang sebab sebab kejahatan yang dalam hal ini adalah pelanggaran lalulintas dipelajari secara khusus dalam etiologi kriminal. Dalam kajian etiologi kriminal faktor penyebab terjadinya pelanggaran lalu lintas bisa karena faktor yang bersifat biologis, psikis dan sosio kultural. Pelanggaran lalu lintas yang disebabkan oleh faktor manusia bisa ditelusuri dari aspek biologis dan psikis yang terkait dengan faktor orangnya. Sedangkan, kajian tentang faktor yang berupa jalan maupun kendaraan secara etiologi kriminal bisa ditelusuri dari sosio kultural.

Masyarakat dengan tingkat perkembangannya dapat menimbulkan tingkat tinggi rendahnya suatu pelanggaran lalu lintas baik yang terkait faktor manusianya maupun jalan dan kendaraan yang dihasilkannya termasuk ketersediaan rambu rambu lalu lintas yang 
melengkapi fasilitas terselenggaranya tertib lalu lintas, bisa juga terjadinya adanya pelanggaran lalu lintas dikarenakan kurang tersedianya sarana jalan dengan rambu-rambu yang kurang memadai yang dapat menyebabkan atau menimbulkan terjadinya kecelakaan. Biasanya terjadinya kecelakaan ini aparat penegak hukum mencari jenis pelanggaran yang kemungkinan dilakukan oleh pelaku pelaku pelanggaran lalu lintas.

Secara kriminologi kurangnya ketersediaan sarana jalan dan ramburambu lalu lintas secara kritis merupakan proses yang melatar belakangi terjadinya kecelakaan yang berada dan menjadi tanggung jawab bukan hanya pada pengguna jalan melainkan juga menjadi tanggung jawab pemerintah.

Pelanggaran rambu lalu lintas tersebut didominasi oleh pengendara yang melanggar rambu larangan, pengendara yang nekat melawan arus serta menerobos lampu merah.Semakin kompleksnya masalah tersebut, maka penulis tertarik untuk mengkaji dalam bentuk skripsi dengan judul : “TINJAUAN KRIMINOLOGI
TERHADAP FAKTOR PENYEBAB

PELANGGARAN RAMBU LALU LINTAS OLEH PENGENDARA SEPEDA MOTOR DI KOTA SEMARANG “.

\section{RUMUSAN MASALAH}

1. Аpa faktor-faktor yang menyebabkan pelanggaran rambu lalu lintas oleh pengendara sepeda motor di Kota Semarang ?

2. Bagaimana kajian kriminologi terhadap pelanggaran rambu lalu lintas oleh pengendara sepeda motor di Kota Semarang?

\section{TUJUANDAN MANFAAT}

PENELITIAN

Adapun tujuan yang ingin dicapai dalam tulisan ini adalah sebagai berikut:

1. Untuk menganalisis faktor-faktor yang menyebabkan pelanggaran rambu lalu lintas oleh pengendara sepeda motor di Kota Semarang.

2. Untuk menganalisis kajian kriminologi terhadap pelanggaran rambu lalu lintas oleh pengendara sepeda motor di Kota Semarang. 
Manfaat dari penulisan ini terdiri dari manfaat teoritis dan manfaat praktis :

1. Secara teoritis diharapkan hasil penelitian ini dapat menambah pengetahuan serta sumbangan dalam pengembangan Ilmu Hukum Pidana Indonesia secara umum, dan secara khusus untuk Fakultas Hukum Universitas Stikubank Semarang.

2. Bagi pihak Kepolisian dan Pemerintah dapat melaksanakan secara tegas peraturan yang terdapat dalam Undang-Undang Republik Indonesia No. 22 Tahun 2009 tentang Lalu Lintas dan Angkutan Jalan.

3. Secara praktis hasil penelitian ini diharapkan dapat memberikan tambahan informasi dan referensi bagi siapa saja yang membutuhkan khususnya mahasiswa Fakultas Hukum yang mempelajari tentang Kriminologi.

\section{METODE PENELITIAN}

Metode yang digunakan dalam penelitian ini adalah yuridis sosiologis.Yuridis merupakan suatu pendekatan yang menggunakan asas dan prinsip hukum yang berasal dari peraturan-peraturan tertulis, sosiologis merupakan suatu pendekatan yang bertujuan untuk memperjelas keadaan yang sesungguhnya di masyarakat terhadap masalah yang diteliti dengan kata lain memberikan arti penting pada langkah-langkah observasi. Dalam penelitian ini metode dilakukan dengan meneliti dan mengumpulkan data primer yang diperoleh secara langsung melalui penelitian terhadap objek penelitian dengan cara observasi dan wawancara dengan responden atau narasumber yang berhubungan dengan permasalahan yang dihadapi dalam penelitian ini.

\section{PEMBAHASAN}

\section{Pengertian kriminologi}

Secara etimologi kriminologi berasal dari kata crimien yang berarti kejahatan, dan logos yang berarti pengetahuan atau ilmu pengetahuan, sehingga kriminologi merupakan ilmu pengetahuan tentang kejahatan.Istilah kriminologi pertama kali digunakan oleh P.Topinard, seorang ahli antropologi Perancis,sedangkan istilah yang dipakai sebelumnya adalah antropologi criminal.Secara umum 
kriminologi bertujuan mempelajari kejahatan dari berbagai aspek, sehingga pemahaman tentang fenomena kejahatan akan bisa diperoleh dengan baik.

\section{Pengertian Pelanggaran Lalu Lintas}

Didalam pengertian umum yang diatur oleh UULLAJ (Pasal 1 UU No. 22 Tahun 2009), tidak ditemukan adanya pengertian secara limitative tentang apa yang dimaksud dengan pelanggaran lalu lintasPelanggaran lalu lintas adalah suatu perbuatan atau perkara melewati, melalui dengan tidak sah, menabrak, menyalahi, melawan, yang berhubungan dengan arus bolak-balik, hilir mudik atau perjalanan dijalan, perhubungan antara satu tempat dengan tempat yang lain dengan menggunakan kendaraan bermotor.

Konsep Kejahatan dan Pelanggaran Kejahatan adalah perbuatanperbuatan yang meskipun tidak ditentukan dalam undang-undang, sebagai perbuatan pidana, telah dirasakan sebagai suatu perbuatan yang bertentangan dengan tata hukum (onrecht) sehingga meskipun perbuatan tersebut tidak dirumuskan dalam undang-undang menjadi tindak pidana tetapi orang tetap menyadari perbuatan tersebut adalah kejahatan dan patut dipidana, istilahnya disebut rechtsdelict (delik hukum).Suatu perbuatan dapat disebut pelanggaran apabila perbuatan perbuatan yang sifatnya melawan hukumnya baru dapat diketahui setelah adanya undang-undang (wet) yang menentukan demikian. Masyarakat baru menyadarai hal tersebut merupakan tindak pidana karena perbuatan tersebut tercantum dalam undang-undang, istilahnya disebut wetsdelict (delik undang-undang).

Jenis-jenis Pelanggaran Rambu Lalu Lintas

Adapun jenis-jenis pelanggaran rambu lalu lintas berdasarkan UndangUndang Nomor 22 Tahun 2009 tentang Lalu Lintas dan Angkutan Jalan, diatur dalam Pasal 106 ayat (4)yang menyatakan :

(4) Setiap orang yang mengemudikan kendaraan bermotor di jalan wajib mematuhi ketentuan :

a. Rambu perintah atau rambu larangan 
b. Marka jalan

c. Alat pemberi isyarat lalu lintas

d. Gerakan lalu lintas

e. Berhenti dan parkir

f. Peringatan dengan bunyi dan sinar

g. Kecepatan maksimal atau minimal

Faktor-faktor yang menyebabkan pelanggaran rambu lalu lintas oleh pengendara sepeda motor di Kota Semarang

Lalu lintas merupakan salah satu sarana komunikasi masyarakat yang memegang peranan vital dalam memperlancar pembangunan yang kita laksanakan. Masalah lalu lintas merupakan salah satu masalah yang berskala nasional yang berkembang seirama dengan perkembangan masyarakat.Kenyataan yang sering di temui sehari-hari adalah masih banyak pengemudi yang belum siap mental, terutama pengemudi angkutan umum dan masyarakat itu sendiri. Mereka saling mendahului tanpa memperdulikan keselamatan dirinya sendiri dan orang lain. Beberapa kecelakaan lalu lintas yang terjadi, sebenarnya dapat dihindari bila diantara pengguna jalan bisa berprilaku disiplin, sopan dan saling menghormati.

Ada 3 (Tiga) faktor utama penghambat terlaksananya UndangUndang Nomor 22 Tahun 2009 tentang Lalu lintas dan Angkutan jalan yakni :

\section{aFaktor Manusia}

Faktor Manusia merupakan faktor yang paling berperan penting dalam pelaksanaan Undang-Undang Nomor 22 Tahun 2009 tentang Lalulintas dan Angkutan jalan sekaligus merupakan faktor penghambat paling utama. Hal ini dikarenakan kurangnya pemahaman masyarakat untuk menjaga keselamatannya dalam berlalulintas dengan mematuhi peraturan-peraturan di dalam Undang-Undang Nomor 22 Tahun 2009 tentang Lalulintas dan Angkutan jalan seperti mengenakan Helm saat berkendara, membawa SIM dan STNK serta melengkapi kelengkapan-kelengkapan kendaraan seperti Spion, Lampu, Klakson dan lain sebagainya.

\section{bFaktor Penegak Hukum}

Faktor penegak hukum atau Polisi Lalulintas merupakan faktor pendukung terlaksananya Undang- 
Undang Nomor 22 Tahun 2009 tentang Lalulintas dan Angkutan jalan juga merupakan faktor penghambat terlaksananya UndangUndang Nomor 22 Tahun 2009 tentang Lalulintas dan Angkutan jalan. Hal ini disebabkan karena kurangnya kesadaran aparat kepolisian dalam melaksanakan tugasnya sebagai pengawas terhadap Undang-Undang nomor 22 tahun 2009 tentang Lalulintas dan Angkutan jalan. Hal ini dapat dilihat dari jawaban koresponden yang mengatakan bahwa "kurangnya aparat kepolisian yang berjaga di pos polisi bahkan kandangkala tidak ada polisi yang berjaga di pos polisi”.

\section{c Faktor Sarana Prasarana}

Faktor sarana dan prasarana selain berperan sebagai pendukung juga berperan sebagai penghambat terlaksananya Undang-Undang Nomor 22 Tahun 2009 tentang Lalulintas dan Angkutan jalan.hal ini dikarenakan semakin berkurangnya sarana seperti rusaknya ramburambu lalulintas bahkan banyaknya rambu-rambu lalu lintas yang hilang.
Kajian Kriminologi Terhadap Pelanggaran Rambu Lalu Lintas Oleh Pengendara Sepeda Motor Di Kota Semarang

Dalam kajian kriminologi kejahatan mencakup dalam hal pelanggaran karena pelanggaran dapat di lihat dalam perspektif kriminologi yaitu :

\section{a. Perspektif Biologis}

Perspektif Biologis dapat di lihat dari ciri-ciri fisik, contohnya seperti yang sering melakukan pelanggaran rambu lalu lintas yang lebih di dominasi perempuan, umur remaja sekitar 1625tahun karena umur remaja masih dalam hal pencarian jati diri dan biasanya di sengaja untuk melanggar rambu lalu lintas misal rambu traffic light, melawan arus dan rambu larangan. Pelanggaran rambu lalu lintas mengapa di dominasi perempuan karena perempuan berani mengeyel dengan polisi, membantah kalau telah melakukan pelanggaran. Ini biasanya terjadi pelanggaran rambu parker, sudah jelas dilarang parkir namun tetap nekat parkir di tempat larangan parkir, kalau sudah terjaring operasi dari Dishub atau Satlantas marah dan balik mencaci maki petugas, dengan alasan karena sebentar, dekat dari tujuan. 
Padahal petugas tak mau tahu dengan alasan tersebut, jika melanggar di tindak karena sudah tertempel rambu larangannya.

\section{b. Perspektif Psikologis}

Perspektif Psikologis dapat dilihat karena faktor kesadaran pengendara sepeda motor yang memang sering tidak mau taat peraturan rambu lalu lintas, menyepelekan dan menganggap remeh peraturan. Faktor kedisiplinan dan ketidak jeraan pengendara sepeda motor juga masuk dalam perspektif psikologis karena kurangnya disiplin misal pengendara terburu-buru mau tidak mau pengendara dijalan pasti mengebut dan mengendarai kendaraannya dengan kecepatan tinggi, lampu traffic light di terobos demi mengejar waktu. Ketidakjeraan pengendara juga mempengaruhi terjadinya pelanggaran karena sudah pernah melakukan pelanggaran nekat melakukan lagi karena penerapan tilang yang kurang memberi efek jera atau karena pengendara memiliki saudara, teman atau kenalan polisi sehingga apabila melakukan pelanggaran bisa bebas.

\section{c. Perspektif Sosiologis}

Perspektif Sosiologis dapat dilihat dari faktor budaya yang berkembang di masyarakat.Faktor budaya masyarakat yang memang tak mau taat peraturan terutama peraturan berlalu lintas sehingga masyarakat seperti sudah biasa bila melanggar tanpa ada rasa salah atau takut.Dari pihak penegak hukum juga yang tidak tegas dalam menindak sehingga kurang member efek jera bagi si pelanggar.

\section{SIMPULAN}

1. Faktor-faktor yang menyebabkan pelanggaran rambu lalu lintas oleh pengendara sepeda motor di Kota Semarang antara lain disebabkan oleh adanya ketidakdisplinan pengendara sepeda motor yaitu pengendara sepeda motor yang tidak mau mematuhi aturan yang berlaku yaitu berhenti di belakang marka saat lampu traffic light menyala merah, adanya faktor kesengajaan pengendara sepeda motor dalam memarkir kendaraannya di atas trotoar pengendara sepeda motor parkir di tempat larangan parkir dan kepurapuraan pengendara sepeda motor 
yang tidak tahu adanya rambu larangan parkir.

2. Kajian kriminologi terhadap pelanggaran rambu lalu lintas oleh pengendara sepeda motor di kota Semarang dapat di lihat dari perspektif :

a. Perspektif Biologis dapat di lihat dari ciri-ciri fisik, contohnya seperti yang sering melakukan pelanggaran rambu lalu lintas yang lebih di dominasi perempuan, umur remaja sekitar 16-25tahun karena umur remaja masih dalam hal pencarian jati diri dan biasanya di sengaja untuk melanggar rambu lalu lintas misal rambu traffic light, melawan arus dan rambu larangan. Pelanggaran rambu lalu lintas mengapa di dominasi perempuan karena perempuan berani mengeyel dengan polisi, membantah kalau telah melakukan pelanggaran. Ini biasanya terjadi pelanggaran rambu parker, sudah jelas dilarang parkir namun tetap nekat parkir di tempat larangan parkir, kalau sudah terjaring operasi dari Dishub atau Satlantas marah dan balik mencaci maki petugas, dengan alasan karena sebentar, dekat dari tujuan. Padahal petugas tak mau tahu dengan alasan tersebut, jika melanggar di tindak karena sudah tertempel rambu larangannya.

b. Perspektif Psikologis dapat dilihat karena faktor kesadaran pengendara sepeda motor yang sering tidak mau taat peraturan rambu lalu lintas, menyepelekan dan menganggap remeh peraturan. Faktor kedisiplinan dan ketidak jeraan pengendara sepeda motor juga masuk dalam perspektif psikologis karena kurangnya disiplin misal pengendara terburu-buru mau tidak mau pengendara dijalan pasti mengebut dan mengendarai kendaraannya dengan kecepatan tinggi, lampu traffic light di terobos demi mengejar waktu. Ketidak jeraan pengendara juga mempengaruhi terjadinya pelanggaran karena sudah pernah melakukan 
pelanggaran nekat melakukan lagi karena penerapan tilang yang kurang memberi efek jera atau karena pengendara memiliki saudara, teman atau kenalan polisi sehingga apabila melakukan pelanggaran bisa bebas.

c. Perspektif Sosiologis dapat dilihat dari faktor budaya yang berkembang di masyarakat. Faktor budaya masyarakat yang memang tak mau taat peraturan terutama peraturan berlalu lintas sehingga masyarakat seperti sudah biasa bila melanggar tanpa ada rasa salah atau takut. Dari pihak penegak hukum juga yang tidak tegas dalam menindak sehingga kurang member efek jera bagi si pelanggar.

\section{DAFTAR PUSTAKA \\ Buku}

Barda Nawawi Arief. Berbagi Aspek Kebijakan Penegakan Pembangunan Hukum Pidana. Bandung: Citra Aditya Bakti. 1998

Kebijakan Hukum Pidana. Bunga Rampai
Hukum Pidana.
Masalah

Penegakan Hukum dan Kebijakan Hukum Pidana dakan Penanggulanga Kejahatan . Jakarta : Kencana, 2010

IS.Susanto, Diktat Kriminologi.,Semarang, Fakultas Hukum Universitas Diponegoro, 1990

--------------...Kriminologi. Fakultas

Hukum. (Semarang :Universitas Diponegoro, 2005

J.E. Sahetapy dan Mardjono Reksodiputro.Parodos dalam kriminolog. Jakarta. Rajawali. 1989

Muladi dan Barda Nawawi Arief, Teori-Teori dan Kebijakan Pidana,Bandung: Alumni, 1984

Naning Rondlon, Menggairahkan Kesadaran Hukum Masyarakat dan Disiplin Penegak Hukum dan Lalu Lintas, (Jakarta : Bina Ilmu, 2008

Ronny Hanitijo Soemitro,Metodologi Penelitian Hukum dan Jurimetri, Ghalia Indonesia,, Jakarta, 1995

Soerjono Soekanto, Pengantar Penelitian Hukum, UI Press, Jakarta, 2012,

Topo Santoso dan Eve Achjani Zulva, Kriminologi,(Jakarta : Grafindo, 2003

\section{Undang-undang}

Undang-undang Nomor 22 Tahun 2009 Tentang Lalu Lintas dan Angkutan Jalan 
Artikel

Imam Yuda Saputra, Operasi Zebra Candi 2017 di Semarang Jaring 8.351

Pelanggar. Rabu, 15 November 2017
08:50 WIB http://www.Semarangpos.

com, diakses tanggal 10 Desember 2017 